\title{
A VEGETAÇÃO DO CAMPUS DA UNIVERSIDADE FEDERAL DE SERGIPE: FLORÍSTICA E FITOSSOCIOLOGIA
}

\author{
THE FEDERAL UNIVERSITY OF SERGIPE VEGETATION, SÃO CRISTÓVÃO: \\ FLORISTIC AND PHYTOSOCIOLOGY
}

\begin{abstract}
Silvio Henrique Menezes Gomes ${ }^{1}$, Robério Anastácio Ferreira², Anabel Aparecida de Mello³, Liziane Rodrigues dos Santos ${ }^{4}$, Natali Aparecida Santana ${ }^{5}$, Francineide Bezerra Gonçalves ${ }^{6}$, Leila Rafaela da Costa Santos ${ }^{7}$
\end{abstract}

\begin{abstract}
RESUMO
O Campus da Universidade Federal de Sergipe está em processo de expansão física de sua estrutura interna desde 2005 e, como consequência, mais de 1100 árvores jovens e adultas foram suprimidas. Esta circunstância conduziu à necessidade de se realizar este trabalho, com o objetivo de analisar a composição florística e a estrutura fitossociológica do Campus. Realizou-se um censo das árvores (CAP $\geq 15 \mathrm{~cm}$ ) em toda extensão da universidade, no período de dezembro de 2014 a janeiro de 2015. Foram coletadas as variáveis CAP, a altura e área de copa. Os parâmetros avaliados foram a Densidade Absoluta (DA); Densidade Relativa (DR); Dominância Absoluta (DoA); Dominância Relativa (DoR) e IVC (Índice de Valor de Cobertura). Foram contabilizados 2.382 indivíduos, distribuídos em 26 famílias botânicas, 76 gêneros e 96 espécies. Com base no número de indivíduos, conforme sua origem, obtevese um percentual de $51,44 \%$ para as nativas e $48,56 \%$ para exóticas. A espécie que apresentou maior IVC foi a Clitoria fairchildiana R.A. Howard. A cobertura total de copa de todos os indivíduos foi equivalente a 16,85 ha e $40,86 \%$ do total da área.
\end{abstract}

Palavras-chave: Mata Atlântica; Arborização; Inventário; Paisagismo.

\section{ABSTRACT}

The Campus of the Federal University of Sergipe is in process of physical expansion of its internal structure since 2005 and, consequently, more than 1100 young and adult trees have been suppressed. This circumstance led to the need to carry out this work, with the objective of analyzing the floristic composition and the phytosociological structure of the Campus. A census of trees $(\mathrm{CBH} \geq 15 \mathrm{~cm})$ was carried out throughout the university during the period from December 2014 to January 2015. The variables collected were: $\mathrm{CBH}$, height and crown area. The parameters evaluated were Absolute Density (AD); Relative Density (DR); Absolute Dominance (DoA); Relative Dominance (DoR) and IVC (Coverage Value Index). A total of 2,382 individuals were enrolled in 26 botanical families, 76 genera and 96 species. Based on the number of individuals, according to their origin, it was obtained a percentage of $51.44 \%$ for the native and $48.56 \%$ for exotic. The species with the highest IVC was Clitoria fairchildiana R.A. Howard. The total crown cover of all individuals was equivalent to 16.85 ha and $40.86 \%$ of the total area.

Keywords: Atlantic Forest; Afforestation; Inventory; Landscaping.

\footnotetext{
Recebido em 02.09.2017 e aceito em 05.01.2018

1 Engenheiro Florestal. Mestre. Universidade Estadual do Sudoeste da Bahia. Vitória da Conquista/BA. Email: silviohmgomes@gmail.com

2 Engenheiro Florestal. Dr. Prof. Associado, Universidade Federal de Sergipe. São Cristóvão/SE. Email: roberioaf@yahoo.com.br 3 Engenheira Florestal. Dr ${ }^{\mathrm{a}}$. Prof ${ }^{\mathrm{a}}$ Associada, Universidade Federal de Sergipe. São Cristóvão/SE. < anabel_mello@yahoo.com.br>

4 Engenharia Florestal. Graduanda. Universidade Federal de Sergipe. São Cristóvão/SE. Email: lizyfloresta19@gmail.com

5 Engenharia Florestal. Graduanda. Universidade Federal de Sergipe. São Cristóvão/SE. Email: nataliknd@gmail.com

6 Engenheira Florestal. Mestre. Universidade Federal de Feira de Santana. Feira de Santana/BA. Email:

francineidegoncalves88@gmail.com

7 Engenheira Florestal. Bacharel. Universidade Federal de Sergipe. São Cristóvão/SE. Email: leilaraf.costa@hotmail.com
} 


\section{INTRODUÇÃO}

As árvores, em uma abordagem microclimática, atuam sobre o bem estar humano no ambiente por meio de suas características naturais, proporcionando conforto térmico para transeuntes e veículos, redução da poluição sonora, melhoria da qualidade do ar, redução da amplitude térmica, sequestro de carbono, abrigo para pássaros e equilíbrio estético, o que controla a discrepância entre a ambiência humana e componentes físicos-arquitetônicos (ABREU; LABAKI, 2010; SILVA; GONZALEZ; SILVA FILHO, 2011; OLDFIELD et al., 2013).

Em geral, nas universidades, o componente arquitetônico e o meio natural são comuns no escopo dos elementos que compõem a paisagem, envolvendo toda problemática assimilada às áreas verdes de vias públicas, tais como praças e avenidas (SANTOS et al., 2011; SOUZA et al., 2011).

Alguns trabalhos realizados sobre composição florística nos espaços acadêmicos veem mostrando uma alta incidência de espécies exóticas. Nesses trabalhos, os percentuais encontram-se entre 40 e $60 \%$ do número total de indivíduos, evidenciando-se a grande utilização dessas espécies na arborização desses espaços verdes, o que pode ser considerado um alto percentual se comparado à grande diversidade da flora brasileira (CARVALHO; ROQUE; GUEDES, 2007; ALMEIDA JÚNIOR, 2009; COSTA; MACHADO, 2009; BRIANEZI et al., 2013; CUPERTINO; EISENLOHR, 2013).

Este fato pode estar relacionado ao desconhecimento dos aspectos econômicos, fisiológicos e ecológicos das espécies nativas, que pode vir a ser um dos motivos à não popularização de seu uso na arborização, para busca de uma identidade local e regional, especialmente na maior escolha de espécies exóticas. Deste modo, deve-se priorizar a utilização de espécies alóctones da flora brasileira a fim de evitar possíveis conflitos nos atributos paisagísticos, bem como na dinâmica ecológica das comunidades que possuem aspectos intrínsecos às características da vegetação (CARVALHO; ROQUE; GUEDES, 2007).

Com a necessidade da reestruturação do Campus para atender aos novos cursos criados e o ingresso do novo contingente de pessoal (docentes, servidores e discentes), a Universidade Federal de Sergipe ampliou sua estrutura física no período onde se iniciaram os planos do governo federal para o aprimoramento do ensino superior no Brasil, o REUNI. Segundo Alves (2010), no período compreendido entre 2004 e 2008 esta ampliação resultou no surgimento de novos cursos de graduação, mestrado e doutorado, necessitando-se a construção de novos prédios e reforma de alguns já existentes para atender tal demanda, o que acarretou na supressão de 240 indivíduos arbóreos adultos. Isto culminou no primeiro levantamento florístico e fitossociológico da Universidade, realizado no período de 2008 e 2009 (ALMEIDA JÚNIOR, 2009) e na necessidade de um novo estudo para conhecimento das 
características das áreas verdes do Campus. Entretanto, no período de 2008 a 2011, mais de 400 indivíduos adultos e mais de 700 árvores jovens, plantadas nos projetos de arborização, e com idade superior a um ano, foram suprimidas.

Para Chaves et al. (2013) o estudo de composição florística e fitossociológica é de fundamental importância para conhecer a estrutura vegetacional, a fim de se obter informações quanti-qualitativas sobre a área de estudo. O mesmo ainda salienta que não é somente para fins de conhecimento, mas também para o desenvolvimento de modelos de conservação e recuperação de áreas degradadas.

Portanto, este trabalho foi realizado com o objetivo de analisar a composição florística e fitossociológica, após a expansão da estrutura física do Campus da Universidade Federal de Sergipe, em São Cristóvão, para auxiliar na gestão das áreas verdes existentes e tentar conservar o patrimônio e a diversidade da sua flora.

\section{MATERIAL E MÉTODOS}

\section{Caracterização da área}

A área de estudo está localizada nos limites físicos da Universidade Federal de Sergipe, Campus “José Aloísio Campos”, no município de São Cristóvão, Sergipe, situada nas coordenadas $10^{\circ} 55^{\prime} 32^{\prime \prime S}$ e 3706'08”W (Figura 1). O clima é tropical chuvoso com verão seco e períodos chuvosos entre os meses de abril a agosto, tipo As, conforme classificação de Köppen, atingindo temperatura média anual de $25,5^{\circ} \mathrm{C}$, umidade relativa do ar média de $75 \%$ e precipitação média de $1.200 \mathrm{~mm}$ (MELO et al., 2006). A área que corresponde ao Campus compreende o total de $411.918 \mathrm{~m}^{2}$. O solo local é o Argissolo Vermelho-Amarelo Distrófico arênico Tb A moderado, franco-arenoso (EMPRESA BRASILEIRA DE PESQUISA AGROPECUÁRIA (EMBRAPA), 2006).

O campus está inserido no bioma Mata Atlântica e, segundo classificação do IBGE, constitui-se de Floresta Estacional Semidecidual, possuindo ainda um remanescente de vegetação nativa, em área de reserva, com exemplares de espécies intrínsecas ao bioma (SANTOS et al., 2007; MALTA; SOUZA; SOUZA, 2012). Apesar de constar como fragmento de vegetação nativa que margeia a área do Campus, seu componente arbóreo, mesclado à sua estrutura física, é descaracterizado devido ao alto grau de espécies exóticas (WHITE et al., 2011).

A estrutura física do Campus envolve áreas destinadas a estacionamentos, didáticas para aulas presenciais, complexo administrativo, ginásio e centro poliesportivo, departamentos, 
ilhas comerciais, de vivência e laboratórios. Apresenta também um espaço para produção de mudas florestais, agroecologia, hospital veterinário e biotério.

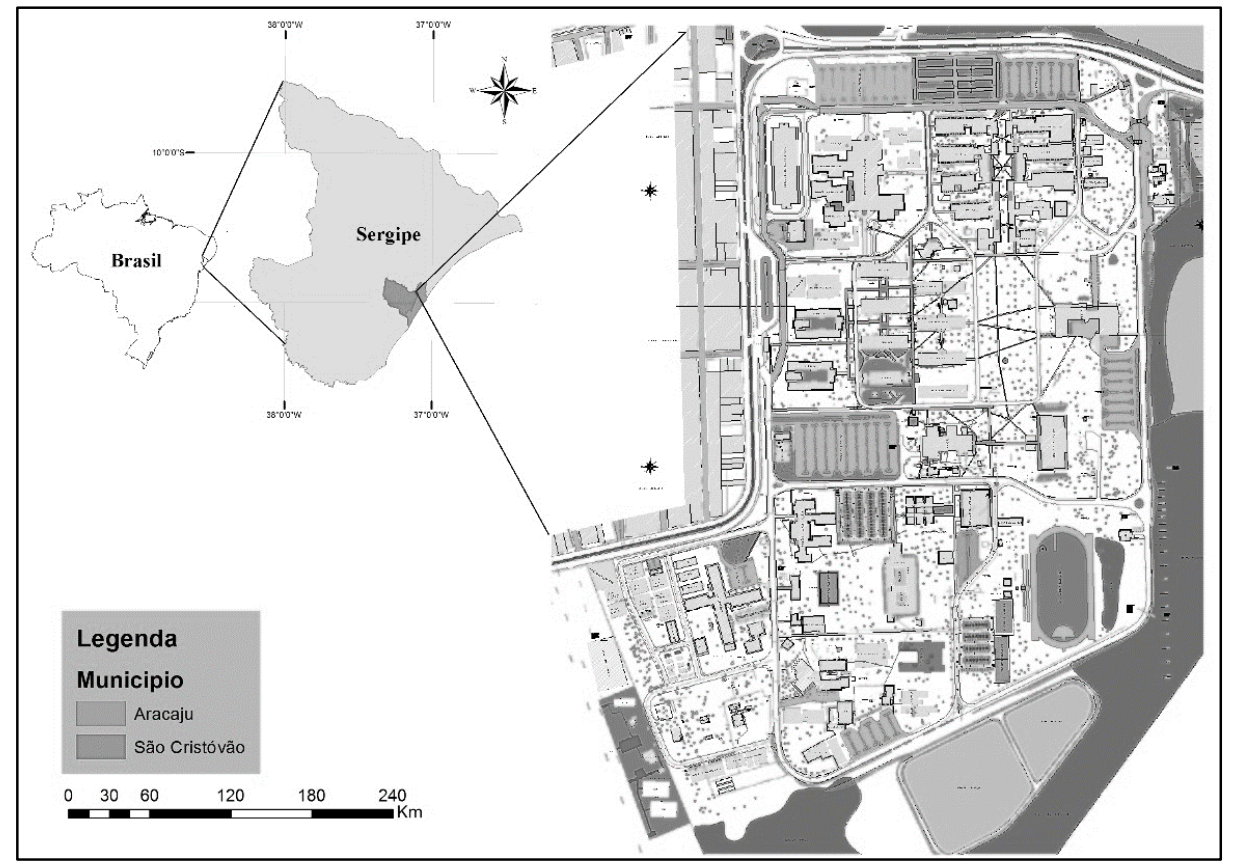

Figura 1. Planta baixa cedida pela DIPRO/UFS do perímetro da Universidade Federal de Sergipe. Pontos no mapa são os indivíduos georreferenciados no ano de 2012

Figure 1 Floor plan courtesy by DIPRO/UFS of the perimeter of the Federal University of Sergipe. Points on the map are the trees georeferenced in 2012

A área utilizada para o cálculo da estrutura horizontal, para avaliação do comportamento dos indivíduos e sua ocupação espacial na área de estudo foi de $411.918 \mathrm{~m}^{2}$, referente à área que envolve apenas o perímetro cercado do Campus São Cristóvão, o que excetua as Áreas de Preservação Permanente e seu entorno. Vale salientar que a área utilizada no presente estudo difere da utilizada por Almeida Júnior (2009), devido ao novo zoneamento da Universidade realizado em 2012.

\section{Obtenção dos dados}

Foi realizado o censo das árvores inseridas no perímetro cercado da universidade, no período de dezembro de 2014 a janeiro de 2015. Nas avaliações realizadas no Campus, foram obtidas as variáveis para determinação da estrutura horizontal e vertical de ocupação da vegetação remanescente, além da medição das copas.

Foram mensurados todos os indivíduos com CAP $\geq 15 \mathrm{~cm}$, tanto os de maior porte quanto os novos indivíduos que atingiram o critério de inclusão, plantados através dos projetos de arborização do Campus no período de 2009 a 2011. As árvores foram georeferenciadas no ano de 2012 (um total de 2.341 pontos), utilizando-se GPS geodésico com precisão de $5 \mathrm{~mm}$. Os novos indivíduos não georeferenciados em 2012, foram sinalizados no mapa impresso para 
futuro georeferenciamento. Os dados do mapa foram utilizados para busca, catalogação e identificação através de seus nomes populares e científicos em campo (Figura 1).

Para obtenção dos dados dendrométricos foram medidas as seguintes variáveis em campo:

a) Altura total: consiste na medição da altura desde o colo da árvore até sua última gema, utilizando para medição um clinômetro (modelo Haglöf);

b) Circunferência a altura do peito (CAP): obtenção da circunferência através de fita métrica a 1,30 m de altura da árvore. A transformação em diâmetro (DAP) se deu conforme: $D A P=C A P / \pi$

c) Área de copa (AC): medição das duas projeções perpendiculares das copas no solo (D1 e D2) com auxílio de trena graduada de $30 \mathrm{~m}$. O cálculo se baseou no formato elipsoidal da copa em $\mathrm{m}^{2}$ pela equação: $A C=(\pi * D 1 * D 2) / 4$

Os dados foram anotados em planilha contendo os campos acima mencionados, incluindo o nome popular e científico da espécie, para posterior análise e quantificação.

Todas as espécies foram identificadas de acordo com o material botânico (exsicatas), comparadas através da consulta em literatura baseada em materiais catalogados no herbário da própria Universidade (Manual de Dendrologia com espécies florestais nativas e exóticas do Campus) (FERREIRA et al., 2013). O sistema de classificação adotado foi o APG III (2009). As espécies foram também divididas conforme sua origem, classificadas entre nativas e exóticas, sendo estas consideradas quando originárias de outro país.

\section{Parâmetros Fitossociológicos}

Os parâmetros fitossociológicos utilizados foram selecionados conforme metodologia sugerida por Chaves et al. (2013), por meio das seguintes fórmulas:

a) Densidade Absoluta (DA): DA = ni / área

Em que: ni - número de indivíduos da espécie i.

b) Densidade Relativa (DR): $\mathrm{DR}=\mathrm{ni} / \mathrm{N}$ *100

Sendo: ni - número de indivíduos da espécie i; $\mathrm{N}$ - número total da população.

c) Dominância Absoluta (DoA): DoA = gi / área

Onde: gi - área seccional da espécie i; gi - $\pi *$ Dap $^{2} / 40000$; Dap - Diâmetro a 1,3 m.

d) Dominância Relativa (DoR): DoR $=(\mathrm{gi} / \mathrm{G}){ }^{*} 100$

Em que: $\mathrm{G}$ - somatório de todas as áreas seccionais ( $\mathrm{gi}$ ) de todas as espécies.

e) Índice de Valor de Cobertura (IVC): IVC = DR + DoR

$\mathrm{Na}$ avaliação da estrutura vertical do componente arbóreo da universidade, os indivíduos foram classificados em 3 classes de estratos diferentes, que são: $E 1$ : $H<5,28$; E2: 
5,28 $\leq H<13,25$; E3: $H \geq 13,25$, onde $H$, é a altura da árvore. Segundo Souza e Soares (2013), os parâmetros fitossociológicos da estrutura vertical em adição aos da estrutura horizontal, conferem uma análise mais completa da importância ecológica das espécies, sobretudo as estimativas dos parâmetros de posição sociológica de regeneração natural. $\mathrm{Na}$ análise vertical das florestas naturais primárias inequiâneas, são utilizados quatro estratos: superior, médio, inferior e sub-bosque sendo que, por convenção, utiliza-se apenas os três primeiros (SOUZA; SOARES, 2013).

Para análise dos parâmetros fitossociológicos de estruturas horizontal e vertical, foi utilizado o programa Mata Nativa v.3 (licenciado) para a Universidade Federal de Sergipe, com o auxílio do Excel v. 2007 para confecção dos gráficos e tabelas.

\section{RESULTADOS E DISCUSSÃO}

Os aspectos da arborização no Campus de São Cristóvão muito se assemelham às características da arborização das principais vias, bairros e praças de Aracaju (WHITE et al., 2011). Isto se dá pela incidência de determinadas espécies como a Pithecelobium dulce (Roxb.) Benth. (mata-fome) e Cocus nucifera L. (coqueiro) (LIMA NETO et al., 2007) e presença das famílias botânicas Arecaceae, Fabaceae e Bignoniaceae (MATOS et al., 2010). No censo realizado entre 2014 e 2015 foram encontrados 2.382 indivíduos arbóreos inseridos no perímetro cercado da Universidade Federal de Sergipe (UFS), distribuídos em 26 famílias botânicas, 76 gêneros e 96 espécies, sendo que destas, 9 não foram identificadas (7 por não apresentarem material botânico completo e 2 delas devido à ausência de copa, impossibilitando a sua identificação) (Tabela 1).

Estes números foram maiores quando comparado ao estudo de Almeida Júnior (2009), no qual contabilizou-se um total de 2.108 indivíduos adultos (censo) no Campus da Universidade Federal de Sergipe, distribuídos em 25 famílias botânicas, 57 gêneros e 72 espécies e observou que $63 \%$ das espécies eram nativas e $37 \%$ exóticas, sendo a Clitoria fairchildiana R. A. Howard (sombreiro) com maior IVC. E aos encontrados por Macêdo et al. (2012) na UFRN, com um total de 45 espécies, por Costa e Machado (2009) na UESPI, com 46 espécies distribuídas em 20 famílias. White et al. (2011) para identificar a erva-de-passarinho (Struthanthus polyrhizus Mart. e Struthanthus vulgaris Mart. Reif) presente nas espécies arbóreas do Campus no mesmo local, encontraram 40 espécies, 38 gêneros e 16 famílias, sendo Fabaceae e Anacardiaceae as famílias com o maior número de espécies no levantamento florístico. Vale salientar que este estudo não envolveu o censo e sim o uso de parcelas, sendo o número total de indivíduos amostrados iguais a 903 espécimes arbóreos. 
Tabela 1. Lista das espécies encontradas em levantamento florístico dos indivíduos arbóreos da Universidade Federal de Sergipe, São Cristóvão, 2014

Table 1. List of species found in floristic survey of individual trees of the Federal University of Sergipe, São Cristóvão, 2014

\begin{tabular}{|c|c|c|c|}
\hline Família & Nome científico & Nome vulgar & Or. \\
\hline \multirow{7}{*}{ Anacardiaceae } & Anacardium occidentale L. & Cajueiro & $\mathrm{N}$ \\
\hline & Mangifera indica L. & Mangueira & $\mathrm{E}$ \\
\hline & Myracrodruon urundeuva Allemão & Aroeira-do-sertão & $\mathrm{N}$ \\
\hline & Schinus terebinthifolius Raddi & Aroeira & $\mathrm{N}$ \\
\hline & Spondias mombim L. & Cajá & $\mathrm{N}$ \\
\hline & Spondias purpurea L. & Seriguela & $\mathrm{E}$ \\
\hline & Tapirira guianensis Aubl. & Pau-pombo & $\mathrm{N}$ \\
\hline \multirow{3}{*}{ Annonaceae } & Annona cacans Warm. & Araticum-cagão & $\mathrm{N}$ \\
\hline & Annona muricata $\mathrm{L}$. & Graviola & $E$ \\
\hline & Annona squamosa L. & Pinha & $\mathrm{E}$ \\
\hline \multirow{2}{*}{ Apocynaceae } & Hancornia speciosa Gomes & Mangabeira & $\mathrm{N}$ \\
\hline & Himatanthus obovatus (Müll. Arg.) Woodson & Pau-de-leite & $\mathrm{N}$ \\
\hline \multirow{5}{*}{ Arecaceae } & Cocos nucifera L. & Coqueiro & $\bar{E}$ \\
\hline & Butia odorata (Barb. Rodr.) Noblick & Butiazeiro & $\mathrm{N}$ \\
\hline & Dypsis lutescens $\mathrm{H}$. Wendl & Areca-bambu & $E$ \\
\hline & Licuala grandis $\mathrm{H}$. Wendl. & Palmeira-leque & $\mathrm{E}$ \\
\hline & Roystonea regia (kunth) O.F. Cook & Palmeira-imperial & $\mathrm{E}$ \\
\hline \multirow{6}{*}{ Bignoniaceae } & Crescentia amazonica Ducke & Cuia & $\mathrm{N}$ \\
\hline & Handroanthus impetiginosus (Mart. Ex DC.) Mattos & Ipê-roxo & $\mathrm{N}$ \\
\hline & Jacaranda brasiliana (Lam.) Pers. & Caroba & $\mathrm{N}$ \\
\hline & Jacaranda macrantha Cham. & Jacarandá & $\mathrm{N}$ \\
\hline & Tabebuia aurea (Silva Manso) Benth. \& Hook. F. ex S. Moore & Craibeira & $\mathrm{N}$ \\
\hline & Tecoma stans (L.) Juss. Ex Kunth & Ipê-mirim & $\mathrm{E}$ \\
\hline Burseraceae & Protium heptaphyllum (Aubl.) Marchand & Amescla & $\mathrm{N}$ \\
\hline Cannabaceae & Trema micrantha (L.) Blume & Grandiúva & $\mathrm{N}$ \\
\hline Casuarinaceae & Casuarina equisetifolia L. & Casuarina & $\mathrm{E}$ \\
\hline \multirow{2}{*}{ Chrysobalanaceae } & Hirtella racemosa Lam. & Bula-cinza & $\mathrm{N}$ \\
\hline & Licania tomentosa (Benth.) Fritsch & Oiti & $\mathrm{N}$ \\
\hline Combretaceae & Terminallia catappa L. & Amendoeira & $\mathrm{E}$ \\
\hline Dilleniaceae & Curatella americana $\mathrm{L}$. & Lixeira & $\mathrm{N}$ \\
\hline \multirow{8}{*}{ Fabaceae } & Adenanthera pavonina $\mathrm{L}$. & Tento-carolina & $\mathrm{N}$ \\
\hline & Albizia polycephala (Benth.) Killip & Albízia & $\mathrm{N}$ \\
\hline & Anadenanthera colubrina (Vell.) Morong. & Angico-branco & $\mathrm{N}$ \\
\hline & Anadenanthera macrocarpa (Benth.) & Angico-vermelho & $\mathrm{N}$ \\
\hline & Andira fraxinifolia Benth. & Angelim & $\mathrm{N}$ \\
\hline & Bowdichia virgilioides Kunth & Sucupira & $\mathrm{N}$ \\
\hline & Cassia grandis L.f. & Canafístula & $\mathrm{N}$ \\
\hline & Clitoria fairchildiana R.A. Howard & Sombreiro & $\mathrm{N}$ \\
\hline \multirow{11}{*}{ Fabaceae } & Delonix regia (bojer ex Hook.) Raf. & Flamboyant & $E$ \\
\hline & Enterolobium contortisiliquum (Vell.) Morong. & Tamboril & $\mathrm{N}$ \\
\hline & Erythrina indica var. picta B. \& M. & Brasileirinho & $\mathrm{E}$ \\
\hline & Erythrina velutina Wild. & Mulungu & $\mathrm{N}$ \\
\hline & Gliricidia sepium (Jacq.) & Gliricidia & E \\
\hline & Hymenaea courbaril L. & Jatobá & $\mathrm{N}$ \\
\hline & Inga laurina (Sw.) Willd. & Ingazinho & $\mathrm{N}$ \\
\hline & Inga vera Willd. & Ingá & $\mathrm{N}$ \\
\hline & Leucaena leucocephala (Lam.) de Wit & Leucena & $\mathrm{E}$ \\
\hline & Libidibia ferrea var. leiostachya (Benth.) L.P. Queiroz & Pau-ferro & $\mathrm{N}$ \\
\hline & Lonchocarpus sericeus (Poir) DC & Falso-ingá & $\mathrm{N}$ \\
\hline
\end{tabular}




\begin{tabular}{|c|c|c|c|}
\hline Família & Nome científico & Nome vulgar & Or. \\
\hline \multirow{9}{*}{ Fabaceae } & Machaerium aculeatum Raddi. & Mau-vizinho & $\mathrm{N}$ \\
\hline & Mimosa caesalpiniifolia Benth. & Sabiá & $\mathrm{N}$ \\
\hline & Paubrasilia echinata (Lam.) E. Gagnon, H. C. Lima \& G. P. Lew & Pau-brasil & $\mathrm{N}$ \\
\hline & Pithecellobium dulce (Roxb.) Benth. & Mata-fome & $E$ \\
\hline & Poincianella pyramidalis (Tul.) L.P. Queiroz & Catingueira & $\mathrm{N}$ \\
\hline & Prosopis juliflora (Sw.) DC. & Algaroba & $E$ \\
\hline & Pterocarpus violaceus Vogel & Sangueiro (aldrago & $\mathrm{N}$ \\
\hline & Schizolobium parahyba (Vell.) S.F. Blake & Guapuruvú & $\mathrm{N}$ \\
\hline & Senna siamea (Lam.) H. S. Irwin \& R.C. Barneby & Cassia-siâmea & $E$ \\
\hline \multirow{2}{*}{ Lauraceae } & Ocotea (cf.) notata (Nees \& Mart.) & Imbúia (louro) & $\mathrm{N}$ \\
\hline & Persea americana Mill. & Abacateiro & $\mathrm{E}$ \\
\hline Lecythidaceae & Eschweilera ovata (Cambess.) Miers & Biriba & $\mathrm{N}$ \\
\hline Malpighiaceae & Byrsonima sericea DC. & Murici & $\mathrm{N}$ \\
\hline \multirow{4}{*}{ Malvaceae } & Ceiba speciosa (A.St.-Hil.) Ravenna & Paineira & $\mathrm{N}$ \\
\hline & Pachira aquatica Aubl. & $\begin{array}{l}\text { Castanha-do- } \\
\text { maranhão }\end{array}$ & $\mathrm{N}$ \\
\hline & Sterculia chicha A. St.-Hil. Ex Turpin & Chichá & $\mathrm{N}$ \\
\hline & Talipariti pernambucense (Arruda) Bovini & Algodão-da-praia & $\mathrm{N}$ \\
\hline Meliaceae & Azadirachta indica A. Juss. & $\mathrm{Nim}$ & $E$ \\
\hline \multirow{3}{*}{ Moraceae } & Artocarpus heterophyllus Lam. & Jaqueira & $E$ \\
\hline & Ficus elastica Roxb. Ex Hornem. & Ficus-elástica & $E$ \\
\hline & Ficus retusa L. & Ficus & $E$ \\
\hline Moringaceae & Moringa oleifera (Lam.) & Moringa & $\mathrm{E}$ \\
\hline \multirow{8}{*}{ Myrtaceae } & Campomanesia sp. & Guabiroba & $\mathrm{N}$ \\
\hline & Corymbia citriodora (Hook.) K.D. Hill \& L.A.S. Johnson & Eucalipto-citriodor & $E$ \\
\hline & Eugenia uniflora L. & Pitanga & $\mathrm{N}$ \\
\hline & Myrcia obovata (O. berg) Nied. & Murta-branca & $\mathrm{N}$ \\
\hline & Psidium guajava L. & Goiabeira & $\mathrm{N}$ \\
\hline & Psidium rufum Mart. DC. & Araçá & $\mathrm{N}$ \\
\hline & Syzygium jambolanum (Lam.) DC. & Jamelão & $E$ \\
\hline & Syzygium malaccense (L.) Merr. \& L.M. Perry & Jambeiro & $\mathrm{E}$ \\
\hline Rhamnaceae & Zizyphus joazeiro Mart. & Juazeiro & $\mathrm{N}$ \\
\hline \multirow{2}{*}{ Rubiaceae } & Genipa americana L. & Jenipapo & $\mathrm{N}$ \\
\hline & Morinda citrifolia L. & Noni & $E$ \\
\hline Rutaceae & Citrus sp. & Limoeiro & $E$ \\
\hline Salicaceae & Casearia sylvestris Sw. & Camarão & $\mathrm{N}$ \\
\hline Sapindaceae & Sapindus saponaria L. & Saboneteira & $\mathrm{N}$ \\
\hline Urticaceae & Cecropia pachystachya Trécul & Embaúba & $\mathrm{N}$ \\
\hline Verbenaceae & Vitex polygama Cham. & Maria-preta & $\mathrm{N}$ \\
\hline-- & morfoespécie 1 & -- & -- \\
\hline-- & morfoespécie 2 & -- & -- \\
\hline-- & morfoespécie 3 & -- & -- \\
\hline-- & morfoespécie 4 & -- & -- \\
\hline-- & morfoespécie 5 & -- & -- \\
\hline-- & morfoespécie 6 & -- & -- \\
\hline-- & morfoespécie 7 & -- & -- \\
\hline-- & morfoespécie 8 & -- & -- \\
\hline-- & morfoespécie 9 & -- & -- \\
\hline
\end{tabular}

Por outro lado, foram menores do que os encontrados por Carvalho, Roque e Guedes (2007) na UFBA, com 131 espécies, distribuídas em 100 gêneros e 31 famílias. Isso demonstra 
que o Campus está em uma posição aceitável dentro do patamar de espécies encontradas em outros campi pelo país.

Apesar do alto número de pontos fornecidos pelo GPS, muitos indivíduos não foram encontrados. No total, foi constatado que 299 pontos verificados no mapa não foram localizados em campo. Isso infere que de 2012 até 2014, foram suprimidos um total de 299 indivíduos além dos já suprimidos em anos anteriores.

Em comparação ao censo anterior realizado (ALMEIDA JUNIOR, 2009), foram identificadas 18 novas espécies: Butia odorata (Barb. Rodr.) Noblick (butiazeiro) (1), Trema micrantha (L.) Blume (grandiúva) (4), Schizolobium parahyba (Vell.) S.F. Blake (guapuruvu) (1), Poincianella pyramidalis (Tul.) L.P. Queiroz (catingueira) (1), Inga vera Willd. (ingá) (2), Lonchocarpus sericeus (poir) DC (falso-ingá) (25), Gliricidia sepium (Jacq.) (gliricídia) (14), Ocotea (cf.) notata (Ness \& Mart.) (imbuia) (4), Sterculia chicha A. St.-Hil. Ex Turpin (chichá) (3), Campomanesia sp. (guabiroba) (1), Eugenia uniflora L. (pitanga) (1), Psidium rufum Mart. DC. (araçá) (3), Vitex polygama Cham. (maria-preta) (1); Pterocarpus violaceus Vogel (sangueiro) (1), Citrus sp. (limoeiro) (1), Morinda citrifolia (noni) (3), Moringa oleifera (Lam.) (moringa) (32) e Machaerium aculeatum Raddi. (mau-vizinho) (6).

As famílias que obtiveram maior representatividade foram: Anacardiaceae (22,34\%) e Fabaceae (Faboideae) (14,86\%). No trabalho realizado por Santos et al. (2007) em fragmento florestal no entorno da Universidade, constatou-se também a predominância dessas famílias (Anacardiaceae e Fabaceae (Faboideae)).

Em relação ao percentual de indivíduos quanto a sua origem, houve a predominância de espécies nativas com $51,44 \%$, em relação às exóticas com 48,56\%. Para o número de espécies quanto à sua origem, obteve-se um total de 66,28\% de nativas e 33,72\% de exóticas (Figura 2). Observa-se que houve um aumento de 3\% no número de espécies nativas desde o levantamento realizado por Almeida Júnior (2009), onde foram encontrados percentuais de $63 \%$ para nativas e $37 \%$ para exóticas. Os dados evidenciam que grande parte dos indivíduos suprimidos ao longo dos anos foi de espécies exóticas, implicando em um decréscimo de $7,44 \%$ desde o levantamento de Almeida Júnior (2009). Nesse sentido, Cupertino e Eisenlohr (2013), avaliando a similaridade florística de 17 universidades brasileiras (5 do Nordeste e 12 de outras regiões) constataram um maior percentual de uso de espécies nativas $(57,43 \%)$ em detrimento de exóticas (42,57\%) nesses espaços. No entanto, enfatizaram que esse número é relativamente alto em apenas 3 das 17 universidades avaliadas. No mesmo estudo, comentam que a proximidade entre as instituições, a nível regional, traz maiores similaridades em termos de espécies. 


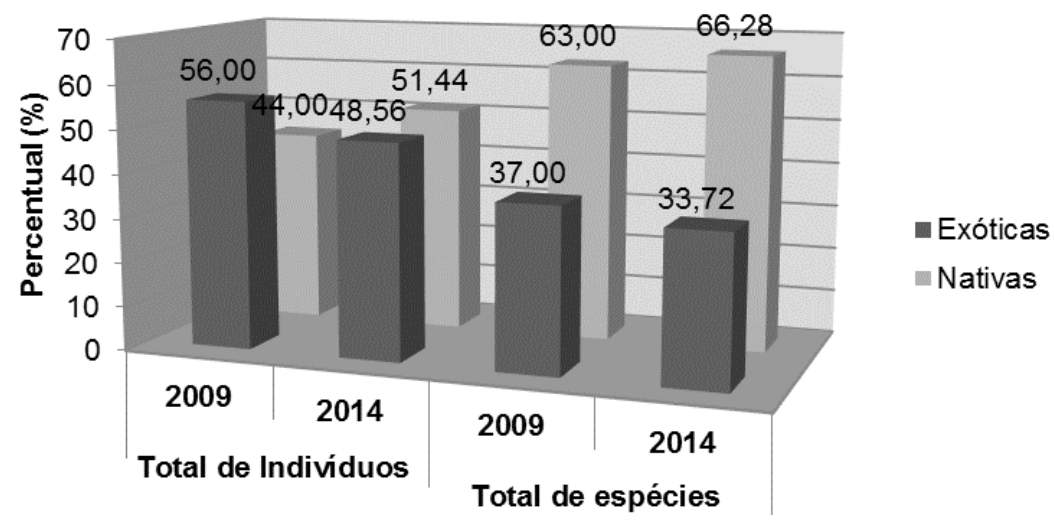

Figura 2. Comparativo dos percentuais do número total de espécies e de indivíduos conforme sua origem, na Universidade Federal de Sergipe, Campus de São Cristóvão, entre os dados apresentados por Almeida Júnior (2009) e os dados aferidos em 2014

Figure 2. Comparison of percentage of the total number of species and individuals as their origin, in the Federal University of Sergipe, Campus at São Cristóvão, between the data presented by Almeida Júnior (2009) and the assessed data in 2014

Em relação ao número de indivíduos por família, as com maior expressividade foram: Anacardiaceae (22,34\%), Fabaceae (Faboideae) (14,86\%), Meliaceae (10,35\%), Arecaceae (Palmae) (10,22\%) e Fabaceae (Mimosoideae) (9,54\%) e Myrtaceae (7,39\%). Estes valores foram semelhantes ao encontrado por Almeida Júnior (2009), principalmente nas famílias Anacardiaceae e Arecaceae (Palmae), com os percentuais de 22,33\% e 16,89\%, respectivamente. As duas famílias com os maiores percentuais também foram encontradas por Santos et al. (2007) avaliando a florística e fitossociologia em um fragmento florestal no entorno da Universidade Federal de Sergipe, na bacia hidrográfica do Rio Poxim, constatando que as famílias mais importantes foram Anacardiaceae, Fabaceae (Faboideae) e Annonaceae, sendo as espécies com maior índice de importância a Clitoria fairchildiana, Annona sp., Syzygium jambolanum Lam. (jamelão), Tapirira guianensis Aubl. (pau-pombo) e Cecropia pachystachya Trécul (embaúba) (Tabela 2).

As espécies que apresentaram as maiores densidades absolutas foram: Clitoria fairchildiana (6,51), Azadirachta indica (5,95), Cocos nucifera $(5,05)$, Anacardium occidentale (4.64) e Mangifera indica $(3,01)$ (Tabela 1). A densidade absoluta tem o principal objetivo de demonstrar os aspectos essenciais na composição florística, fazendo assim uma análise da vegetação e encontrar um valor que permita uma visão mais abrangente da estrutura das espécies ou que caracterize a importância de cada espécie no conjunto total do povoamento. Os valores encontrados expressam uma alta ocupação espacial da espécie Clitoria fairchildiana nesse levantamento, diferente do encontrado por Almeida Júnior (2009), onde a espécie Cocos nucifera obteve o maior valor. Entretanto, observa-se que a espécie Cocos nucifera, apesar do menor número de indivíduos neste novo levantamento, manteve-se com um valor de densidade absoluta semelhante ao do censo realizado por Almeida Júnior (2009), onde o valor encontrado foi de 5,85 . 
Tabela 2. Parâmetros fitossociológicos dos indivíduos arbóreos da Universidade Federal de Sergipe, São Cristóvão, 2014

Table 2. Phytosociological parameters of arboreal individuals of the Federal University of Sergipe, São Cristóvão, 2014

\begin{tabular}{|c|c|c|c|c|c|c|c|c|c|}
\hline Família & Nome científico & Nome vulgar & Or. & $\mathrm{Ni}$ & DA & DR & DoA & DoR & IVC \\
\hline \multirow{7}{*}{ Anacardiaceae } & Anacardium occidentale L. & Cajueiro & $\mathrm{N}$ & 191 & 4,64 & 8,02 & 0,59 & 8,71 & 16,73 \\
\hline & Mangifera indica L. & Mangueira & $\mathrm{E}$ & 124 & 3,01 & 5,21 & 0,59 & 8,79 & 14,00 \\
\hline & Myracrodruon urundeuva Allemão & Aroeira-do-sertão & $\mathrm{N}$ & 1 & 0,02 & 0,04 & 0,00 & 0,01 & 0,05 \\
\hline & Schinus terebinthifolius Raddi & Aroeira & $\mathrm{N}$ & 120 & 2,91 & 5,04 & 0,26 & 3,92 & 8,96 \\
\hline & Spondias mombim L. & Cajá & $\mathrm{N}$ & 2 & 0,05 & 0,08 & 0,00 & 0,03 & 0,12 \\
\hline & Spondias purpurea L. & Seriguela & $E$ & 1 & 0,02 & 0,04 & 0,00 & 0,01 & 0,05 \\
\hline & Tapirira guianensis Aubl. & Pau-pombo & $\mathrm{N}$ & 90 & 2,19 & 3,78 & 0,24 & 3,57 & 7,34 \\
\hline \multirow{3}{*}{ Annonaceae } & Annona squamosa L. & Pinha & $E$ & 6 & 0,15 & 0,25 & 0,00 & 0,01 & 0,27 \\
\hline & Annona cacans Warm. & Araticum-cagão & $\mathrm{N}$ & 2 & 0,05 & 0,08 & 0,00 & 0,00 & 0,09 \\
\hline & Annona muricata L. & Graviola & $\mathrm{E}$ & 1 & 0,02 & 0,04 & 0,00 & 0,00 & 0,04 \\
\hline \multirow[t]{2}{*}{ Apocynaceae } & $\begin{array}{l}\text { Himatanthus obovatus (Müll. Arg.) } \\
\text { Woodson }\end{array}$ & Pau-de-leite & $\mathrm{N}$ & 7 & 0,17 & 0,29 & 0,00 & 0,04 & 0,34 \\
\hline & Hancornia speciosa Gomes & Mangabeira & $\mathrm{N}$ & 1 & 0,02 & 0,04 & 0,00 & 0,02 & 0,06 \\
\hline \multirow{5}{*}{ Arecaceae } & Butia odorata (Barb. Rodr.) Noblick & Butiazeiro & $\mathrm{N}$ & 1 & 0,02 & 0,04 & 0,00 & 0,01 & 0,05 \\
\hline & Cocos nucifera L. & Coqueiro & $E$ & 208 & 5,05 & 8,73 & 0,27 & 4,00 & 12,73 \\
\hline & Dypsis lutescens H. Wendl & Areca-bambu & $E$ & 1 & 0,02 & 0,04 & 0,00 & 0,00 & 0,05 \\
\hline & Licuala grandis $\mathrm{H}$. Wendl. & Palmeira-leque & $E$ & 7 & 0,17 & 0,29 & 0,01 & 0,10 & 0,40 \\
\hline & Roystonea regia (kunth) O.F. Cook & Palmeira-imperial & $E$ & 25 & 0,61 & 1,05 & 0,05 & 0,80 & 1,85 \\
\hline \multirow{6}{*}{ Bignoniaceae } & Crescentia amazonica Ducke & Cuia & $\mathrm{N}$ & 2 & 0,05 & 0,08 & 0,00 & 0,02 & 0,11 \\
\hline & $\begin{array}{l}\text { Handroanthus impetiginosus (Mart. Ex } \\
\text { DC.) Mattos }\end{array}$ & Ipê-roxo & $\mathrm{N}$ & 24 & 0,58 & 1,01 & 0,04 & 0,51 & 1,52 \\
\hline & Jacaranda brasiliana (Lam.) Pers. & Caroba & $\mathrm{N}$ & 2 & 0,05 & 0,08 & 0,00 & 0,05 & 0,13 \\
\hline & Jacaranda macrantha Cham. & Jacarandá & N & 13 & 0,32 & 0,55 & 0,02 & 0,36 & 0,90 \\
\hline & $\begin{array}{l}\text { Tabebuia aurea (Silva Manso) Benth. } \\
\text { \& Hook. F. ex S. Moore }\end{array}$ & Craibeira & $\mathrm{N}$ & 37 & 0,90 & 1,55 & 0,09 & 1,34 & 2,89 \\
\hline & Tecoma stans (L.) Juss. Ex Kunth & Ipê-mirim & $\mathrm{E}$ & 14 & 0,34 & 0,59 & 0,00 & 0,04 & 0,63 \\
\hline Burseraceae & Protium heptaphyllum (Aubl.) Marchand & Amescla & $\mathrm{N}$ & 2 & 0,05 & 0,08 & 0,00 & 0,01 & 0,09 \\
\hline Cannabaceae & Trema micrantha (L.) Blume & Grandiúva & $\mathrm{N}$ & 4 & 0,10 & 0,17 & 0,01 & 0,09 & 0,26 \\
\hline Casuarinaceae & Casuarina equisetifolia $\mathrm{L}$. & Casuarina & $\mathrm{E}$ & 19 & 0,46 & 0,8 & 0,06 & 0,91 & 1,71 \\
\hline \multirow{2}{*}{ Chrysobalanaceae } & Hirtella racemosa Lam. & Bula-cinza & $\mathrm{N}$ & 7 & 0,17 & 0,29 & 0,01 & 0,11 & 0,40 \\
\hline & Licania tomentosa (Benth.) Fritsch & Oiti & $\mathrm{N}$ & 14 & 0,34 & 0,59 & 0,04 & 0,65 & 1,23 \\
\hline Combretaceae & Terminallia catappa L. & Amendoeira & $\mathrm{E}$ & 86 & 2,09 & 3,61 & 0,19 & 2,82 & 6,43 \\
\hline Dilleniaceae & Curatella americana L. & Lixeira & $\mathrm{N}$ & 12 & 0,29 & 0,50 & 0,01 & 0,20 & 0,70 \\
\hline \multirow{8}{*}{ Fabaceae } & Adenanthera pavonina $\mathrm{L}$. & Tento-carolina & $\mathrm{N}$ & 17 & 0,41 & 0,71 & 0,08 & 1,25 & 1,96 \\
\hline & Albizia polycephala (Benth.) Killip & Albízia & $\mathrm{N}$ & 2 & 0,05 & 0,08 & 0,01 & 0,11 & 0,19 \\
\hline & $\begin{array}{l}\text { Anadenanthera colubrina (Vell.) } \\
\text { Morong. }\end{array}$ & Angico-branco & $\mathrm{N}$ & 1 & 0,02 & 0,04 & 0,01 & 0,12 & 0,16 \\
\hline & Anadenanthera macrocarpa (Benth.) & Angico-vermelho & $\mathrm{N}$ & 24 & 0,58 & 1,01 & 0,01 & 0,12 & 1,13 \\
\hline & Andira fraxinifolia Benth. & Angelim & $\mathrm{N}$ & 23 & 0,56 & 0,97 & 0,10 & 1,43 & 2,4 \\
\hline & Bowdichia virgilioides Kunth & Sucupira & N & 9 & 0,22 & 0,38 & 0,01 & 0,17 & 0,54 \\
\hline & Cassia grandis L.f. & Canafístula & $\mathrm{N}$ & 13 & 0,32 & 0,55 & 0,02 & 0,22 & 0,76 \\
\hline & Clitoria fairchildiana R.A. Howard & Sombreiro & $\mathrm{N}$ & 268 & 6,51 & 11,25 & 1,48 & 21,87 & 33,12 \\
\hline \multirow{11}{*}{ Fabaceae } & Delonix regia (bojer ex Hook.) Raf. & Flamboyant & $E$ & 21 & 0,51 & 0,88 & 0,05 & 0,69 & 1,57 \\
\hline & $\begin{array}{l}\text { Enterolobium contortisiliquum (Vell.) } \\
\text { Morong. }\end{array}$ & Tamboril & $\mathrm{N}$ & 1 & 0,02 & 0,04 & 0,00 & 0,02 & 0,06 \\
\hline & Erythrina indica var. picta B. \& M. & Brasileirinho & E & 2 & 0,05 & 0,08 & 0,00 & 0,01 & 0,10 \\
\hline & Erythrina velutina Wild. & Mulungu & $\mathrm{N}$ & 4 & 0,10 & 0,17 & 0,03 & 0,50 & 0,67 \\
\hline & Gliricidia sepium (Jacq.) & Gliricidia & E & 14 & 0,34 & 0,59 & 0,00 & 0,06 & 0,65 \\
\hline & Hymenaea courbaril L. & Jatobá & N & 2 & 0,05 & 0,08 & 0,00 & 0,03 & 0,11 \\
\hline & Inga laurina (Sw.) Willd. & Ingazinho & $\mathrm{N}$ & 31 & 0,75 & 1,3 & 0,11 & 1,62 & 2,92 \\
\hline & Inga vera Willd. & Ingá & $\mathrm{N}$ & 2 & 0,05 & 0,08 & 0,00 & 0,01 & 0,09 \\
\hline & Leucaena leucocephala (Lam.) de Wit & Leucena & $E$ & 11 & 0,27 & 0,46 & 0,00 & 0,06 & 0,52 \\
\hline & $\begin{array}{l}\text { Libidibia ferrea var. leiostachya } \\
\text { (Benth.) L.P. Queiroz }\end{array}$ & Pau-ferro & $\mathrm{N}$ & 32 & 0,78 & 1,34 & 0,04 & 0,62 & 1,97 \\
\hline & Lonchocarpus sericeus (Poir) DC & Falso-ingá & $\mathrm{N}$ & 25 & 0,61 & 1,05 & 0,01 & 0,14 & 1,19 \\
\hline
\end{tabular}




\begin{tabular}{|c|c|c|c|c|c|c|c|c|c|}
\hline Família & Nome científico & Nome vulgar & Or. & $\mathrm{Ni}$ & DA & DR & DoA & DoR & IVC \\
\hline \multirow{9}{*}{ Fabaceae } & Machaerium aculeatum Raddi. & Mau-vizinho & $\mathrm{N}$ & 6 & 0,15 & 0,25 & 0,00 & 0,02 & 0,27 \\
\hline & Mimosa caesalpiniifolia Benth. & Sabiá & $\mathrm{N}$ & 5 & 0,12 & 0,21 & 0,00 & 0,06 & 0,27 \\
\hline & $\begin{array}{l}\text { Paubrasilia echinata (Lam.) E. } \\
\text { Gagnon, H. C. Lima \& G. P. Lewis }\end{array}$ & Pau-brasil & $\mathrm{N}$ & 45 & 1,09 & 1,89 & 0,03 & 0,46 & 2,35 \\
\hline & Pithecellobium dulce (Roxb.) Benth. & Mata-fome & $E$ & 127 & 3,08 & 5,33 & 0,79 & 11,77 & 17,11 \\
\hline & $\begin{array}{l}\text { Poincianella pyramidalis (Tul.) L.P. } \\
\text { Queiroz }\end{array}$ & Catingueira & $\mathrm{N}$ & 1 & 0,02 & 0,04 & 0,00 & 0,00 & 0,04 \\
\hline & Prosopis juliflora (Sw.) DC. & Algaroba & E & 5 & 0,12 & 0,21 & 0,03 & 0,37 & 0,58 \\
\hline & Pterocarpus violaceus Vogel & $\begin{array}{l}\text { Sangueiro } \\
\text { (aldrago) }\end{array}$ & $\mathrm{N}$ & 1 & 0,02 & 0,04 & 0,00 & 0,01 & 0,06 \\
\hline & $\begin{array}{l}\text { Schizolobium parahyba (Vell.) S.F. } \\
\text { Blake }\end{array}$ & Guapuruvú & $\mathrm{N}$ & 1 & 0,02 & 0,04 & 0,00 & 0,01 & 0,05 \\
\hline & $\begin{array}{l}\text { Senna siamea (Lam.) H. S. Irwin \& } \\
\text { R.C. Barneby }\end{array}$ & Cassia-siâmea & E & 4 & 0,10 & 0,17 & 0,01 & 0,18 & 0,35 \\
\hline \multirow{2}{*}{ Lauraceae } & Ocotea (cf.) notata (Nees \& Mart.) & Imbúia (louro) & $\mathrm{N}$ & 4 & 0,10 & 0,17 & 0,01 & 0,21 & 0,38 \\
\hline & Persea americana Mill. & Abacateiro & $\mathrm{E}$ & 1 & 0,02 & 0,04 & 0,00 & 0,02 & 0,06 \\
\hline Lecythidaceae & Eschweilera ovata (Cambess.) Miers & Biriba & $\mathrm{N}$ & 5 & 0,12 & 0,21 & 0,01 & 0,17 & 0,38 \\
\hline Malpighiaceae & Byrsonima sericea DC. & Murici & $\mathrm{N}$ & 15 & 0,36 & 0,63 & 0,01 & 0,15 & 0,78 \\
\hline \multirow{4}{*}{ Malvaceae } & Ceiba speciosa (A.St.-Hil.) Ravenna & Paineira & $\mathrm{N}$ & 3 & 0,07 & 0,13 & 0,00 & 0,03 & 0,16 \\
\hline & Pachira aquatica Aubl. & $\begin{array}{l}\text { Castanha-do- } \\
\text { maranhão }\end{array}$ & $\mathrm{N}$ & 17 & 0,41 & 0,71 & 0,11 & 1,56 & 2,28 \\
\hline & Sterculia chicha A. St.-Hil. Ex Turpin & Chichá & $\mathrm{N}$ & 3 & 0,07 & 0,13 & 0,00 & 0,00 & 0,13 \\
\hline & $\begin{array}{l}\text { Talipariti pernambucense (Arruda) } \\
\text { Bovini }\end{array}$ & Algodão-da-praia & $\mathrm{N}$ & 6 & 0,15 & 0,25 & 0,01 & 0,19 & 0,44 \\
\hline Meliaceae & Azadirachta indica A. Juss. & $\mathrm{Nim}$ & $E$ & 245 & 5,95 & 10,29 & 0,17 & 2,5 & 12,78 \\
\hline \multirow{3}{*}{ Moraceae } & Artocarpus heterophyllus Lam. & Jaqueira & $E$ & 1 & 0,02 & 0,04 & 0,00 & 0,03 & 0,07 \\
\hline & Ficus elastica Roxb. Ex Hornem. & Ficus-elástica & E & 2 & 0,05 & 0,08 & 0,03 & 0,50 & 0,58 \\
\hline & Ficus retusa L. & Ficus & $\mathrm{E}$ & 39 & 0,95 & 1,64 & 0,05 & 0,79 & 2,43 \\
\hline Moringaceae & Moringa oleifera (Lam.) & Moringa & $E$ & 32 & 0,78 & 1,34 & 0,02 & 0,28 & 1,63 \\
\hline \multirow{8}{*}{ Myrtaceae } & Campomanesia sp. & Guabiroba & $\mathrm{N}$ & 1 & 0,02 & 0,04 & 0,00 & 0,00 & 0,04 \\
\hline & $\begin{array}{l}\text { Corymbia citriodora (Hook.) K.D. Hill \& } \\
\text { L.A.S. Johnson }\end{array}$ & $\begin{array}{l}\text { Eucalipto- } \\
\text { citriodora }\end{array}$ & E & 57 & 1,38 & 2,39 & 0,07 & 0,97 & 3,36 \\
\hline & Eugenia uniflora L. & Pitanga & $\mathrm{N}$ & 1 & 0,02 & 0,04 & 0,00 & 0,00 & 0,04 \\
\hline & Myrcia obovata (O. berg) Nied. & Murta-branca & $\mathrm{N}$ & 17 & 0,41 & 0,71 & 0,01 & 0,21 & 0,92 \\
\hline & Psidium guajava $\mathrm{L}$. & Goiabeira & $\mathrm{N}$ & 4 & 0,10 & 0,17 & 0,00 & 0,05 & 0,22 \\
\hline & Psidium rufum Mart. DC. & Araçá & N & 3 & 0,07 & 0,13 & 0,00 & 0,00 & 0,13 \\
\hline & Syzygium jambolanum (Lam.) DC. & Jamelão & E & 90 & 2,19 & 3,78 & 0,74 & 10,95 & 14,73 \\
\hline & $\begin{array}{l}\text { Syzygium malaccense (L.) Merr. \& } \\
\text { L.M. Perry }\end{array}$ & Jambeiro & $E$ & 2 & 0,05 & 0,08 & 0,01 & 0,07 & 0,15 \\
\hline Rhamnaceae & Zizyphus joazeiro Mart. & Juazeiro & $\mathrm{N}$ & 1 & 0,02 & 0,04 & 0,00 & 0,02 & 0,06 \\
\hline \multirow{2}{*}{ Rubiaceae } & Genipa americana L. & Jenipapo & $\mathrm{N}$ & 3 & 0,07 & 0,13 & 0,00 & 0,07 & 0,19 \\
\hline & Morinda citrifolia L. & Noni & $\mathrm{E}$ & 3 & 0,07 & 0,13 & 0,00 & 0,01 & 0,13 \\
\hline Rutaceae & Citrus sp. & Limoeiro & $E$ & 1 & 0,02 & 0,04 & 0,00 & 0,00 & 0,05 \\
\hline Salicaceae & Casearia sylvestris Sw. & Camarão & $\mathrm{N}$ & 24 & 0,58 & 1,01 & 0,09 & 1,27 & 2,28 \\
\hline Sapindaceae & Sapindus saponaria L. & Saboneteira & $\mathrm{N}$ & 5 & 0,12 & 0,21 & 0,01 & 0,13 & 0,34 \\
\hline Urticaceae & Cecropia pachystachya Trécul & Embaúba & $\mathrm{N}$ & 61 & 1,48 & 2,56 & 0,02 & 0,36 & 2,92 \\
\hline Verbenaceae & Vitex polygama Cham. & Maria-preta & $\mathrm{N}$ & 1 & 0,02 & 0,04 & 0,00 & 0,00 & 0,05 \\
\hline-- & morfoespécie 1 & -- & -- & 1 & 0,02 & 0,04 & 0,00 & 0,01 & 0,05 \\
\hline-- & morfoespécie 2 & -- & -- & 1 & 0,02 & 0,04 & 0,00 & 0,01 & 0,05 \\
\hline-- & morfoespécie 3 & -- & -- & 3 & 0,07 & 0,13 & 0,02 & 0,27 & 0,39 \\
\hline-- & morfoespécie 4 & -- & -- & 2 & 0,05 & 0,08 & 0,00 & 0,04 & 0,12 \\
\hline-- & morfoespécie 5 & -- & -- & 3 & 0,07 & 0,13 & 0,00 & 0,01 & 0,13 \\
\hline-- & morfoespécie 6 & -- & -- & 1 & 0,02 & 0,04 & 0,00 & 0,00 & 0,05 \\
\hline-- & morfoespécie 7 & -- & -- & 1 & 0,02 & 0,04 & 0,00 & 0,00 & 0,04 \\
\hline-- & morfoespécie 8 & -- & -- & 1 & 0,02 & 0,04 & 0,00 & 0,03 & 0,07 \\
\hline-- & morfoespécie 9 & -- & -- & 1 & 0,02 & 0,04 & 0,00 & 0,04 & 0,08 \\
\hline TOTAL & & & & 2382 & 57,83 & 100 & 6,75 & 100 & 200 \\
\hline
\end{tabular}


No presente trabalho, foi observada uma incidência de $89,81 \%$ das espécies entre as 10 famílias com os maiores números de indivíduos. Isso mostra que apesar do alto número de espécies, a diversidade florística no Campus São Cristóvão ainda apresenta uma baixa distribuição e alta concentração. Brianezi et al. (2013), na Universidade Federal de Viçosa, também observou que apesar da alta riqueza de espécies encontradas há uma má distribuição no número de indivíduos, com o valor de $50 \%$ do total. Santamour Junior (2004) recomenda que para a prevenção de patogenicidades em espaços urbanos o ideal é que o número de indivíduos por família não ultrapasse os 30\%, demonstrando que a arborização do Campus está aquém desse valor e portanto a um nível satisfatório.

Considerando-se a área total ocupada por todos os indivíduos contabilizados, a área basal foi de $277,83 \mathrm{~m}^{2}\left(6,74 \mathrm{~m}^{2} / \mathrm{ha}\right)$, o que corresponde a 57,82 ind./ha em termos de densidade absoluta total. A cobertura total de copa de todos os indivíduos foi de $168.348 \mathrm{~m}^{2}$, o equivalente a 16,85 ha e 40,86\% de cobertura em relação à área total computada. Esse valor de cobertura de copa foi maior do que o encontrado por Costa e Machado (2009) na UESPI, onde se obteve um total de 37.996,41 $\mathrm{m}^{2}$ de copa (30,17\% da área) em uma área de 126.491 $\mathrm{m}^{2}$. Isso mostra que, apesar do decréscimo dos indivíduos adultos suprimidos durante a expansão, a universidade mantém um percentual aceitável em termos de cobertura de copa, demonstrando um alto índice de sombreamento em suas áreas verdes, quando comparado ao próprio percentual de praças da capital (Aracaju) que encontra-se entre 39 e 68\% de sombreamento (LIMA NETO; SOUZA, 2009). Entretanto, vale salientar que apesar de seu alto índice, a depender das características morfológicas de cada espécie, outros aspectos devem ser avaliados para atestar o conforto térmico e as funções ecológicas em cada espaço. Este mecanismo de análise da vegetação consegue inferir áreas prioritárias para conservação, além de evidenciar informações que norteiem estratégias de gestão, seja no uso de espécies com atributos ecológicos mais condizentes com a realidade local, como para adensar logradouros em que o sombreamento seja escasso e prioritário, a exemplo dos estacionamentos.

O IVC avalia tanto a distribuição da espécie em nível de indivíduo quanto sua distribuição espacial em termos de biomassa, dando pesos iguais a cada uma delas. Os dados evidenciam que não houve diferenças consideráveis entre os dois censos. Isto pode ser explicado porque, apesar do grande número de árvores suprimidas ao longo dos anos, houve uma compensação por parte dos projetos de arborização, além da regeneração natural no pequeno fragmento ao lado do Campo de Atletismo. Outro aspecto é que a área utilizada para cômputo dos principais parâmetros fitossociológicos foi diferente da utilizada por Almeida Júnior (2009), o que pode ter acarretado em distinções já que alguns utilizam a área total na base de cálculo. As espécies que apresentaram os maiores IVC foram: Clitoria fairchildiana 
$(33,12)$, Pithecellobium dulce $(17,11)$, Anacardium occidentale $(16,73)$, Syzygium jambolanum $(14,73)$, Mangifera indica $(14,00)$ e Azadirachta indica $(12,78)$ (Tabela 3).

Tabela 3. Relação das dez espécies com os maiores Índices de Valor de Cobertura (IVC). Dados de 2009 fornecidos por Almeida Júnior (2009) e os últimos valores (2014) aferidos na Universidade Federal de Sergipe, São Cristóvão, 2014

Table 3. List of the ten species with the largest indices of coverage value (IVC). 2009 data provided by Almeida Júnior (2009) and the last values (2014) assessed at the Federal University of Sergipe, São Cristóvão, 2014

\begin{tabular}{lcc}
\multicolumn{1}{c}{ Nome científico } & \multicolumn{2}{c}{ IVC } \\
& 2009*$^{*}$ & $\mathbf{2 0 1 4}$ \\
\hline Clitoria fairchildiana & 31,22 & 33,12 \\
Pithecellobium dulce & 18,09 & 17,11 \\
Anacardium occidentale & 19,93 & 16,73 \\
Syzygium jambolanum & 14,83 & 14,73 \\
Mangifera indica & 16,03 & 14,00 \\
Azadirachta indica & 6,21 & 12,78 \\
Cocos nucifera & 25,57 & 12,73 \\
Schinus terebinthifolius & 6,78 & 8,96 \\
Tapirira guianensis & 3,65 & 7,34 \\
Terminallia catappa & 8,85 & 6,43 \\
\hline
\end{tabular}

Nota: *Almeida Júnior (2009)

Em relação a distribuição diamétrica da população, observa-se um comportamento similar a fragmentos florestais inequiâneos, onde a distribuição se dá em formato de "J" invertido, mostrando os aspectos de regeneração e balanceamento da floresta. Entretanto, o gráfico mostra uma leve anormalidade de picos em algumas classes de diâmetro, evidenciando falta de uniformização no sentido das menores classes para as maiores classes, o que pode ser explicado pelo fato da área estudada ser em um ambiente urbanizado e, portanto, com uma dinâmica diferente em comparação a áreas não antropizadas (Figura 3).

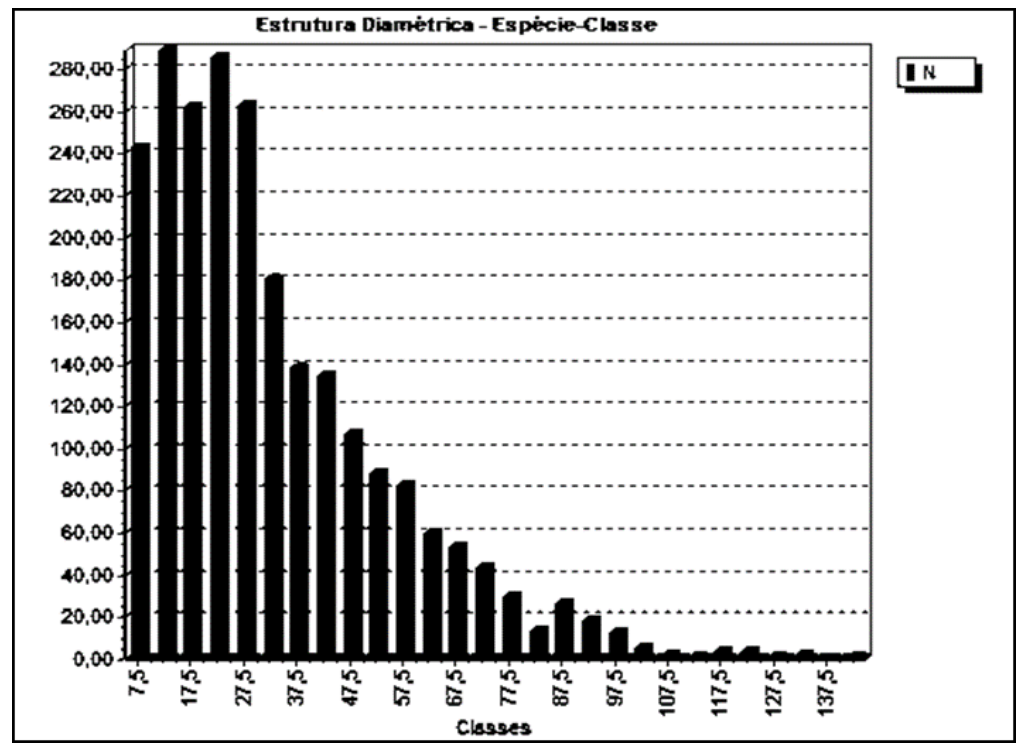

Figura 3. Distribuição das espécies por classe diamétrica dos indivíduos arbóreos da Universidade Federal de Sergipe, São Cristóvão, UFS, 2014. Fonte: Mata Nativa v. 3 (licenciado)

Figure 3. Distribution of the species by diameter class of the arboreal individuals of the Federal University of Sergipe, São Cristóvão, UFS, 2014. Source: Mata Nativa v. 3 (licensed) 
A Figura 3 apresenta uma alta frequência nas classes de menores diâmetros, principalmente nas classes compreendidas entre 17,5 a 27,5 . Isso evidencia que, apesar do maior número de indivíduos encontrados nesse levantamento em comparação ao censo realizado por Almeida Júnior (2009), pôde-se constatar que os novos indivíduos encontram-se nas menores classes diamétricas. Com as ações de plantios de mudas executados pelos projetos de arborização da instituição no período de 2008 a 2010, alguns desses novos indivíduos atingiram o critério mínimo de inclusão e, portanto, foram contabilizados nesse levantamento, o que mostra 0 alto ingresso nas menores classes de diâmetro em detrimento das maiores classes. Outro aspecto seria a regeneração natural em alguns pontos da Universidade, como é o caso do pequeno fragmento formado ao lado do Campo de Atletismo, que demonstrou um alto número de novos indivíduos, em destaque para as espécies Clitoria fairchildiana, Cecropia pachystachya e Tapirira guianensis. A Cecropia pachystachya é uma espécie pioneira e indicadora de ambientes que sofreram algum tipo de perturbação. Nesse sentido, a Universidade criou um déficit com a supressão de indivíduos adultos de maiores classes de diâmetros, o que demonstraria um comportamento diferente no gráfico de distribuição diamétrica em observância às últimas classes à direita, no eixo das abscissas.

Os dados evidenciam alta concentração de indivíduos e espécies no segundo estrato $(5,28 \leq H<13,25)$, em que os indivíduos arbóreos da universidade encontram-se em estágio secundário. Estes valores podem ser atribuídos às características das espécies encontradas, principalmente a espécie Clitoria fairchildiana que tem um comportamento de secundária inicial e portanto de crescimento mais lento em relação às pioneiras, o que atribui um alto índice de indivíduos adultos dessa espécie nesse estrato (200 no segundo estrato) (Tabela 4).

Santos et al. (2007), em estudo em trecho ciliar do Rio Poxim, no entorno da Universidade, classificou a vegetação em seu estrato vertical como de médio porte, com componente arbóreo atingindo o máximo de $15 \mathrm{~m}$ de altura total e, devido ao grau de perturbação, observou que a distribuição espacial vertical é indefinida na maioria dos trechos da área de estudo. Dentro destes aspectos, a estrutura vertical na área cercada do Campus São Cristóvão muito se assemelha com as características do fragmento em seu entorno, principalmente pela alta concentração de indivíduos no médio estrato. Entretanto, vale salientar que houve um número expressivo de indivíduos no estrato superior, com árvores com alturas superiores a $13 \mathrm{~m}$ como é o caso de alguns exemplares da espécie Casuarina equisetifolia, que obteve $73,68 \%$ dos indivíduos concentrados no estrato superior e Cocos nucifera com $54,44 \%$ nesse mesmo estrado e nenhum no estrato inferior. 
Tabela 4. Estrutura vertical dos indivíduos arbóreos dividida em três estratos, São Cristóvão, UFS, 2014 Table 4. Vertical structure of tree individuals divided into three strata, São Cristóvão, UFS, 2014

\begin{tabular}{|c|c|c|c|c|c|c|c|c|c|}
\hline Nome Científico & E1 & E2 & E3 & Total & Nome Científico & E1 & E2 & E3 & Total \\
\hline Clitoria fairchildiana & 26 & 200 & 42 & 268 & Erythrina velutina & 0 & 2 & 2 & 4 \\
\hline Azadirachta indica & 69 & 176 & 0 & 245 & Ocotea (cf.) notata & 0 & 3 & 1 & 4 \\
\hline Cocos nucifera & 0 & 101 & 107 & 208 & Senna siamea & 0 & 0 & 4 & 4 \\
\hline Anacardium occidentale & 24 & 161 & 6 & 191 & Trema micrantha & 0 & 4 & 0 & 4 \\
\hline Pithecellobium dulce & 5 & 80 & 42 & 127 & Psidium guajava & 0 & 4 & 0 & 4 \\
\hline Mangifera indica & 12 & 73 & 39 & 124 & morfoespécie 3 & 0 & 2 & 1 & 3 \\
\hline Schinus terebinthifolius & 27 & 88 & 5 & 120 & Genipa americana & 2 & 1 & 0 & 3 \\
\hline Syzygium jambolanum & 0 & 34 & 56 & 90 & Ceiba speciosa & 1 & 1 & 1 & 3 \\
\hline Tapirira guianensis & 3 & 58 & 29 & 90 & morfoespécie 4 & 2 & 1 & 0 & 3 \\
\hline Terminallia catappa & 29 & 44 & 13 & 86 & Morinda citrifolia & 3 & 0 & 0 & 3 \\
\hline Cecropia pachystachya & 3 & 56 & 2 & 61 & Sterculia chicha & 1 & 2 & 0 & 3 \\
\hline Corymbia citriodora & 0 & 16 & 41 & 57 & Psidium rufum & 2 & 1 & 0 & 3 \\
\hline Paubrasilia echinata & 20 & 25 & 0 & 45 & Ficus elastica & 0 & 1 & 1 & 2 \\
\hline Ficus retusa & 12 & 25 & 2 & 39 & Albizia polycephala & 0 & 0 & 2 & 2 \\
\hline Tabebuia aurea & 8 & 15 & 14 & 37 & Syzygium malaccense & 0 & 1 & 1 & 2 \\
\hline Libidibia ferrea var. leiostachya & 12 & 20 & 0 & 32 & Jacaranda brasiliana & 0 & 2 & 0 & 2 \\
\hline Moringa oleifera & 5 & 27 & 0 & 32 & morfoespécie 5 & 0 & 1 & 1 & 2 \\
\hline Inga laurina & 4 & 22 & 5 & 31 & Spondias mombim & 1 & 0 & 1 & 2 \\
\hline Roystonea regia & 13 & 10 & 2 & 25 & Hymenaea courbaril & 0 & 2 & 0 & 2 \\
\hline Lonchocarpus sericeus & 15 & 10 & 0 & 25 & Crescentia amazonica & 2 & 0 & 0 & 2 \\
\hline Casearia sylvestris & 0 & 20 & 4 & 24 & Erythrina indica var. picta & 2 & 0 & 0 & 2 \\
\hline Handroanthus impetiginosus & 7 & 13 & 4 & 24 & Protium heptaphyllum & 0 & 2 & 0 & 2 \\
\hline Anadenanthera macrocarpa & 3 & 21 & 0 & 24 & Inga vera & 1 & 1 & 0 & 2 \\
\hline Andira fraxinifolia & 2 & 17 & 4 & 23 & Annona cacans & 2 & 0 & 0 & 2 \\
\hline Delonix regia & 13 & 8 & 0 & 21 & Anadenanthera colubrina & 0 & 1 & 0 & 1 \\
\hline Casuarina equisetifolia & 0 & 5 & 14 & 19 & morfoespécie 9 & 0 & 1 & 0 & 1 \\
\hline Pachira aquatica & 2 & 14 & 1 & 17 & Artocarpus heterophyllus & 0 & 1 & 0 & 1 \\
\hline Adenanthera pavonina & 1 & 6 & 10 & 17 & morfoespécie 8 & 0 & 1 & 0 & 1 \\
\hline Myrcia obovata & 1 & 15 & 1 & 17 & Zizyphus joazeiro & 0 & 1 & 0 & 1 \\
\hline Byrsonima sericea & 6 & 9 & 0 & 15 & Hancornia speciosa & 0 & 1 & 0 & 1 \\
\hline Licania tomentosa & 0 & 10 & 4 & 14 & Enterolobium contortisiliquum & 0 & 1 & 0 & 1 \\
\hline Gliricidia sepium & 5 & 9 & 0 & 14 & Persea americana & 0 & 1 & 0 & 1 \\
\hline Tecoma stans & 14 & 0 & 0 & 14 & Pterocarpus violaceus & 0 & 1 & 0 & 1 \\
\hline Jacaranda macrantha & 1 & 11 & 1 & 13 & Spondias purpurea & 0 & 1 & 0 & 1 \\
\hline Cassia grandis & 3 & 10 & 0 & 13 & Schizolobium parahyba & 0 & 1 & 0 & 1 \\
\hline Curatella americana & 4 & 8 & 0 & 12 & morfoespécie 1 & 0 & 1 & 0 & 1 \\
\hline Leucaena leucocephala & 1 & 10 & 0 & 11 & Butia odorata & 0 & 1 & 0 & 1 \\
\hline Bowdichia virgilioides & 2 & 6 & 1 & 9 & morfoespécie 2 & 1 & 0 & 0 & 1 \\
\hline Hirtella racemosa & 3 & 4 & 0 & 7 & Myracrodruon urundeuva & 0 & 1 & 0 & 1 \\
\hline Licuala grandis & 0 & 7 & 0 & 7 & Citrus sp. & 0 & 1 & 0 & 1 \\
\hline Himatanthus obovatus & 0 & 7 & 0 & 7 & morfoespécie 6 & 0 & 1 & 0 & 1 \\
\hline Talipariti pernambucense & 0 & 6 & 0 & 6 & Vitex polygama & 1 & 0 & 0 & 1 \\
\hline Machaerium aculeatum & 5 & 1 & 0 & 6 & Dypsis lutescens & 0 & 1 & 0 & 1 \\
\hline Annona squamosa & 6 & 0 & 0 & 6 & Poincianella pyramidalis & 0 & 1 & 0 & 1 \\
\hline Prosopis juliflora & 0 & 5 & 0 & 5 & Annona muricata & 1 & 0 & 0 & 1 \\
\hline Eschweilera ovata & 0 & 4 & 1 & 5 & Campomanesia sp. & 1 & 0 & 0 & 1 \\
\hline Sapindus saponaria & 1 & 3 & 1 & 5 & morfoespécie 7 & 0 & 1 & 0 & 1 \\
\hline Mimosa Caesalpiniifolia & 2 & 3 & 0 & 5 & Eugenia uniflora & 1 & 0 & 0 & 1 \\
\hline- & - & - & - & - & Total Geral & 393 & 1523 & 466 & 2382 \\
\hline
\end{tabular}

Nota: $\mathrm{E} 1: \mathrm{H}<5,28$; $\mathrm{E2}: 5,28 \leq \mathrm{H}<13,25 ; \mathrm{E} 3: \mathrm{H} \geq 13,25 ; \mathrm{H}$ : Altura da árvore 


\section{CONCLUSÕES}

Foram registradas 96 espécies, pertencentes a 76 gêneros, e 26 famílias, sendo que 9 espécies não foram identificadas a nível de espécie.

Houve uma maior incidência de espécies nativas (66,28\%) em detrimento das exóticas (33,72\%). Quanto ao número de indivíduos conforme sua origem, para as nativas obteve-se um percentual de $51,44 \%$ e para exóticas $48,56 \%$.

As espécies que apresentaram o maior número de indivíduos foram Clitoria fairchildiana R.A. Howard (268) e Azadirachta indica A. Juss. (245), e a espécie que obteve maior densidade, dominância absoluta e IVC foi a Clitoria fairchildiana R.A. Howard. No novo levantamento florístico constatou-se um total de 18 espécies novas, sendo estas, butiazeiro, grandiúva, guapuruvu, catingueira, ingá, falso-ingá, gliricídia, imbuia, chichá, guabiroba, pitanga, araçá, maria-preta, sangueiro, limoeiro, moringa e mau-vizinho.

As espécies que apresentaram as maiores densidades absolutas foram: Clitoria fairchildiana (6,51), Azadirachta indica (5,95), Cocos nucifera $(5,05)$, Anacardium occidentale $(4,64)$ e Mangifera indica $(3,01)$. E as espécies que apresentaram os maiores IVC foram: Clitoria fairchildiana (33,12), Pithecellobium dulce (17,11), Anacardium occidentale (16,73), Syzygium jambolanum (14,73), Mangifera indica $(14,00)$ e Azadirachta indica $(12,78)$.

A cobertura total de copa de todos os indivíduos foi de $168.348 \mathrm{~m}^{2}$, o equivalente a 16,85 ha, ou seja, $40,86 \%$ de cobertura do total da área. A distribuição horizontal demonstrou um alto número de espécies inseridas nas menores classes de diâmetro. Em relação à estrutura vertical, a vegetação apresenta uma característica de estrato secundário.

Recomenda-se uma diminuição dos indivíduos exóticos no Campus com a substituição por espécies nativas autóctones em plantios futuros, bem como o enriquecimento no número de indivíduos das espécies nativas já existentes, além da análise para seleção de áreas prioritárias dentro da universidade para conservação da biodiversidade e manutenção das relações da flora e fauna.

\section{AGRADECIMENTOS}

Ao grupo Restauração, MAUAR, Angico e demais membros do grupo de arborização da UFS. 


\section{REFERÊNCIAS}

ABREU, L. V.; LABAKI, L. C. Conforto térmico propiciado por algumas espécies arbóreas: avaliação do raio de influência através de diferentes índices de conforto. Ambiente Construído, Porto Alegre, v. 10, n. 4, p. 103-117, 2010.

ALMEIDA JÚNIOR, P. P. Florística e fitossociologia da vegetação arbórea do Campus da Universidade Federal de Sergipe (UFS), São Cristóvão - Sergipe. São Cristóvão, 2009. 29 f. Monografia (Graduação em Engenharia Florestal) - Universidade Federal de Sergipe, São Cristóvão, 2009.

ALVES, F. A. M. Aplicabilidade de normas ambientais e percepção do ambiente na gestão da Universidade Federal de Sergipe. São Cristóvão, 2010. 163 f. Dissertação (Mestrado em Desenvolvimento e Meio Ambiente) - Universidade Federal de Sergipe, São Cristóvão, 2010.

APG III - The Angiosperm Phylogeny Group. An update of the Angiosperm Phylogeny Group classification for the orders and families of flowering plants: APG III. Botanical Journal of the Linnaean Society. v. 161, p. 128-131, 2009.

BRIANEZI, D.; JACOVINE, L. A. G.; GONÇALVES, W.; ROCHA, S. J. S. S. da. Avaliação da arborização no Campus-Sede da Universidade Federal de Viçosa. Revista da Sociedade Brasileira de Arborização Urbana, Piracicaba, v. 8, n. 4, p. 89-106, 2013.

CARVALHO, G. M. de; ROQUE, N.; GUEDES, M. L. S. Levantamento das espécies arbóreas da Universidade Federal da Bahia, Salvador, Bahia. Sitientibus Série Ciências Biológicas, Feira de Santana, v. 7, n. 4, p. 377-387, 2007.

CHAVES, A. D. C. G.; SANTOS, R. M. de S.; SANTOS, J. O. de; FERNANDES, A. de A.; MARACAJÁ, P. B. A importância dos levantamentos florístico e fitossociológico para conservação e preservação das florestas. ACSA - Agropecuária Científica no Semiárido, Campina Grande, v. 9, n. 2, p. 43-48, 2013.

COSTA, I. S.; MACHADO, R. R. B. A arborização do Campus da UESPI - Poeta Torquato Neto em Teresina - PI: Diagnóstico e Monitoramento. Revista da Sociedade Brasileira de Arborização Urbana, Piracicaba, v. 4, n. 4, p. 32-46, 2009.

CUPERTINO, M. A.; EISENLOHR, P. V. Análise florística comparativa da arborização urbana nos campi universitários do Brasil. Bioscience Journal, Uberlândia, v. 29, n. 3, p. 739-750, 2013.

EMPRESA BRASILEIRA DE PESQUISA AGROPECUÁRIA (EMBRAPA). Centro Nacional de Pesquisa de Solos. Sistema brasileiro de classificação de solos. 2. ed. Rio de Janeiro: Embrapa SPI, 2006. 306p.

FERREIRA, R. A.; OLIVEIRA, D. G. de; ALMEIDA, E. S. de; NASCIMENTO, M. I. C.; PRATA, A. P. do N. Manual de dendrologia: Espécies florestais nativas e exóticas do Campus de São Cristóvão/UFS. São Cristóvão: Editora UFS, 2013. 92p.

LIMA NETO, E. M. de; RESENDE, W. X.; SENA, M. G. D.; SOUZA, R. M. Análise das áreas verdes das praças do bairro centro e principais avenidas da cidade de Aracaju-SE. Revista da Sociedade Brasileira de Arborização Urbana, Piracicaba, v. 2, n. 1, 2007.

LIMA NETO, E. M.; SOUZA, R. M. Índices de densidade e sombreamento arbóreo em áreas verdes públicas de Aracaju, Sergipe. Revista da Sociedade Brasileira de Arborização Urbana, Piracicaba, v. 4, n. 4, p. 47-62, 2009. 
MACÊDO, B. R. M.; LISBOA, C. M. C. A.; CARVALHO, F. G. de. Diagnóstico e diretrizes para a arborização do Campus Central da Universidade Federal do Rio Grande do Norte. Revista da Sociedade Brasileira de Arborização Urbana, Piracicaba, v. 7, n. 1, p. 35-51, 2012.

MALTA, J. A. O.; SOUZA, H. T. R. de; SOUZA, R. M. Dinâmica fitogeográfica em florestas urbanas no entorno do campus de São Cristóvão, Sergipe. Caminhos de Geografia, Uberlândia, v. 13, n. 41, p. 146-158, 2012.

MATOS, E. C. do A.; NASCIMENTO-JÚNIOR, J. E. do; MARIANO, D. L. da S.; OLIVEIRA, A. L. de. Arborização do bairro centro da cidade de Aracaju, Sergipe, e seus organismos associados. Revista da Sociedade Brasileira de Arborização Urbana, Piracicaba, v. 5, n. 4, p. 22-39, 2010.

MELO, A. S.; AGUIAR NETO, A. O.; DANTAS NETO, J.; BRITO, M. E. B.; VIEGAS, P. R. A.; MAGALHÃES, L.T.G.; FERNANDES, P. D. Desenvolvimento vegetativo, rendimento da fruta e otimização do abacaxizeiro cv. Pérola em diferentes níveis de irrigação. Ciências Rurais, Santa Maria, v. 36, n. 1, p. 93-98, 2006.

OLDFIELD, E. E.; WARREN, R. J.; FELSON, A. J.; BRADFORD M. A. Challenges and future directions in urban afforestation. British Ecological Society: Journal of Applied Ecology, v. 50, n. 5, p. 1169-1177, 2013.

SANTAMOUR JÚNIOR, F. S. Trees for urban planting: diversity uniformity, and common sense. In: ELEVITCH, C. R. (Ed.). The overstory book: Cultivating connections with Trees. 2 ed. Holualoa: Permanent Agriculture Resources, 2004. p. 396-399

SANTOS, C. Z. dos; FERREIRA, R. A.; SANTOS, L. R.; SANTOS, L. I.; GRAÇA, D. A. S. da; GOMES, S. H.; PORTO NETO, W. de B.; CORREIA, T. S.; BOSCHESE, A. C. de B. Composição Florística de 25 Vias Públicas de Aracaju - SE. Revista da Sociedade Brasileira de Arborização Urbana, Piracicaba, v. 6, n. 2, p. 125-144, 2011.

SANTOS, M. J.; FREITAS, A. C.; RIBEIRO, G. T.; NASCIMENTO, A. V. S. Florística e fitossociologia no trecho ciliar do Rio Poxim, Município de São Cristóvão, SE. Revista Brasileira de Ciências Agrárias, Recife, v. 2, n. 3, p. 223-227, 2007.

SILVA, I. M. da; GONZALEZ, L. R.; SILVA FILHO, D. F. da. Recursos naturais de conforto térmico: um enfoque urbano. Revista da Sociedade Brasileira de Arborização Urbana, Piracicaba, v. 6, n. 4, p. 35-50, 2011.

SOUZA, A. L. de; FERREIRA, R. A.; MELLO, A. A. de; PlÁCIDO, D. da R.; SANTOS, C. Z. A. dos; GRAÇA, D. A. S. da; ALMEIDA JÚNIOR, P. P. de A.; BARRETTO, S. S. B.; DANTAS, J. D. de M; PAULA, J. W. A.; SILVA, T. L. da; GOMES, L. P. S. Diagnóstico quantitativo e qualitativo da arborização das praças de Aracaju, SE. Revista Árvore, Viçosa, v. 35, n. 6, p. 1253-1263, 2011.

SOUZA, A. L. de; SOARES, C. P. B. Florestas nativas: estrutura dinâmica e manejo. Viçosa: Editora UFV, 2013. 322p.

WHITE, B. L. A.; RIBEIRO, A. de S.; WHITE, L. A. S.; JÚNIOR, J. E. do N. Análise da ocorrência de Erva-de-passarinho na arborização da Universidade Federal de Sergipe, Campus São Cristóvão. Floresta, Curitiba, v. 41, n. 1, p. 1-8, 2011. 